\title{
Impact of an Intrainstitutional Teledermatology Service: Mixed-Methods Case Study
}

Trevor Champagne ${ }^{1}$, BSc, BMath (Hons), MD, FRCP; Peter G Rossos ${ }^{2,3,4}$, MD, MBA, FRCP, FACP; Veronica Kirk ${ }^{2}$, BSc; Emily Seto ${ }^{2,3}$, PEng, PhD

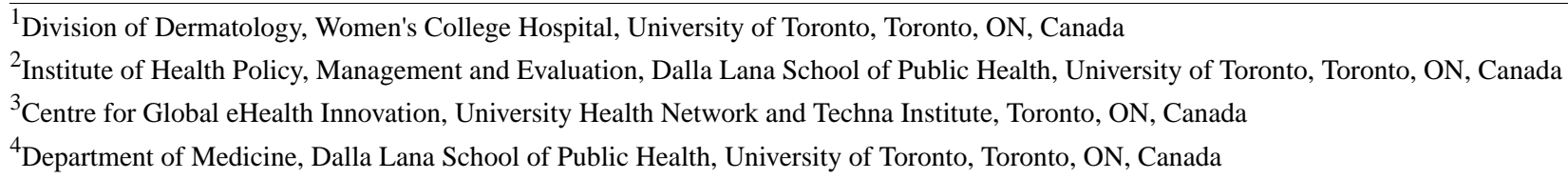

Corresponding Author:

Trevor Champagne, BSc, BMath (Hons), MD, FRCP

Division of Dermatology

Women's College Hospital

University of Toronto

76 Grenville Street, Room 3415

Toronto, ON, M5S 1B2

Canada

Phone: 14163236400 ext 4240

Fax: 14163236236

Email: trevor.champagne@wchospital.ca

\section{Abstract}

Background: Teledermatology provides timely access to consultative dermatology services while reducing the need for travel among patients in rural and underserviced areas. However, knowledge about the potential benefits of such a service in urban areas is limited.

Objective: This study aimed to determine the impact of a geographically unrestricted, intrainstitutional, secure, email teledermatology service for dermatology.

Methods: We employed a mixed-methods approach using chart review, surveys, and semistructured interviews from the Canada Health Infoway Benefits Evaluation Framework. Patient charts were reviewed for demographics, clinical characteristics, and outcomes. Electronic and paper surveys were sent to patients and providers to quantify aspects of the service, such as satisfaction and usability, on a Likert scale. Semistructured interviews of referring providers and a convenience sample of academic consultant dermatologists who were considering teledermatology for their practice were conducted. Interviews were transcribed and analyzed using manual coding and thematic analysis by both the primary author and a second independent reviewer. All results were concurrently triangulated in an overarching analysis.

Results: A total of 76 consultations were reviewed over a period of 18 months, of which $84 \%$ were completely managed without an in-person visit. Only $6 \%$ of rashes required a subsequent in-person visit to a dermatologist for management, compared to $41 \%$ of lesions. In addition, 28\% (21/76) of patients responded to the survey. Patients "strongly agreed" to use the service again, were satisfied with the management of their skin issue, and thought the service saved them time. In general, providers who answered the electronic survey "strongly agreed" that the service demonstrated quality, timeliness, and an educational benefit, but increased their administrative time. A total of 9 interviews of 5 referring providers and 4 dermatologists were completed. Triangulation of all study components supported the hypothesis that teledermatology benefits providers, patients, and the health care system.

Conclusions: Intrainstitutional teledermatology has high satisfaction among patients and providers and saves patients time, even when there are no geographic or systemic barriers to access. This service may be most effective when targeted at rashes rather than lesions. Additional research on the cost-effectiveness and educational benefits of this service is warranted.

(JMIR Dermatol 2018;1(2):e11923) doi: 10.2196/11923

\section{KEYWORDS}

dermatology; e-health; teledermatology 


\section{Introduction}

Teledermatology allows dermatologists to manage patients with generally equivalent clinical outcomes and requires less resources and less time with the consultant than in-person visits [1]. Its impact is evident in geographic areas that do not have timely access to dermatology, which is the most-studied aspect of teledermatology; for example, in the United States, $80 \%$ of dermatologists are clustered in 3 large metropolitan areas [2]. There is a similar disproportionate clustering of dermatologists in metropolitan areas in Canada [3]. These substantial disparities in the geographic distribution of dermatologists have been increasing [4].

Knowledge of the potential of intrainstitutional teledermatology, wherein geographic access is not a factor of the net benefit assessment of the value of teledermatology, is limited. Other pilot studies have assessed the feasibility and diagnostic concordance of these implementations [5], but formal assessments of their impact are lacking.

We hypothesize that teledermatology will have value beyond geographic access if implemented by the consultants and referring physicians intrainstitutionally. We designed this study to investigate the potential benefits, barriers, and impact of teledermatology in such an intrainstitutional setting, where the traditional geographic barriers to access do not exist. We further hoped to identify specific characteristics of the teledermatology service that would be useful for implementing the service at other institutions. Studies have reported the usefulness of teledermatology in only a few specific scenarios, and there is disagreement about the clinical conditions that are suitable for teledermatology in the literature; for example, several studies have reported the potential of teledermatology for identifying any suspicious skin lesions [6,7]; in contrast, the American Telemedicine Association guidelines for teledermatology [8] state that it is difficult to assess pigmented lesions and special sites such as the scalp with teledermatology.

\section{Methods}

\section{Overview}

We performed a mixed-methods evaluation using broad categories of the Canada Health Infoway (CHI) Benefits Evaluation Framework [9] to include at least one aspect of qualitative and quantitative analyses for each category as well as case studies, surveys, and semistructured interviews. The key results were triangulated in a final, overarching analysis. This study was approved by the research ethics boards of Women's College Hospital and the University of Toronto in Toronto, Ontario, Canada.

\section{Design of the Intrainstitutional Teledermatology Service}

Parameters were chosen to balance convenience (encourage use) and pragmatic considerations of the practice guidelines for teledermatology [8]. We selected a store-and-forward design with secondary teledermatology, as it is a funded model in our region, and secure institutional email as a common, accessible technology. Clinically, the referring providers were informed that they could send any request they deemed appropriate and a response would be guaranteed within 1 week. The primary author was the sole consultant providing responses. The details of the implementation are described in Table 1.

Table 1. Components of the intrainstitutional teledermatology service and the rationale for choosing the components.

\begin{tabular}{|c|c|}
\hline Component & Rationale \\
\hline \multicolumn{2}{|l|}{ Modality } \\
\hline Asynchronous & $\begin{array}{l}\text { Most-convenient method for the consultant dermatologist and requires the least amount of coordination } \\
\text { or additional technology }\end{array}$ \\
\hline $\begin{array}{l}\text { Secondary teledermatology (referring } \\
\text { a health care provider to a consultant } \\
\text { dermatologist) }\end{array}$ & $\begin{array}{l}\text { Meets identity and privacy guideline requirements, and secondary teledermatology is a regionally insured } \\
\text { service by the provincial government }\end{array}$ \\
\hline \multicolumn{2}{|l|}{ Technology } \\
\hline Secure intrainstitutional email & $\begin{array}{l}\text { A convenient, ubiquitous technology that is secure; limited to institutional use, with no barrier to entry; } \\
\text { and shared across clinics }\end{array}$ \\
\hline Photography & $\begin{array}{l}\text { Referring providers were requested to provide in-focus images; at least one close-up image; and if } \\
\text { widespread, photos representing the overall distribution }\end{array}$ \\
\hline One-week response time & $\begin{array}{l}\text { A four-fold improvement over existing wait times at our institution, and enough time to discourage urgent } \\
\text { consultations through this service, which would be better provided at an emergency care institution }\end{array}$ \\
\hline Free-form text permitted (no template) & $\begin{array}{l}\text { To permit benefit evaluation, we did not restrict the clinical use of the system or make implicit suggestions } \\
\text { about what conditions would be appropriate }\end{array}$ \\
\hline
\end{tabular}




\section{Data Collection}

\section{Chart Review}

Stored medical records for each consultation were reviewed from service initiation in late 2016 through 2017. All patients were previously registered in the hospital electronic medical record system, as they were a part of the referring family-practice unit. Contact information was collected for emailing or mailing surveys. Demographic information including age and gender was collated. Each chart was reviewed for clinical characteristics including diagnosis and management. For each patient, the hospital-wide electronic medical record was additionally reviewed for evidence of treatment failure, symptom recurrence of the treated dermatosis, or any other pertinent follow-up information.

\section{Referring Provider Survey}

Emails for each referring attending provider who submitted at least one consultation request were collated, and an email invitation from SurveyMonkey [10] was sent to request their participation in an electronic survey assessing satisfaction, time expenditure, educational value, and adverse events, which ranked these parameters on a Likert scale. If the provider did not complete the survey, invitations were resent 2 weeks and 1 month after the initial invitation. Health care providers rated each question on a scale of 1-7, where 1 was "Strongly disagree," 7 was "Strongly agree," and 4 was "Neutral."

\section{Patient Survey}

Patients were invited to participate in a survey assessing satisfaction with the service, potential benefits, and attitudes toward teledermatology. Email invitations were sent to the subset of patients who had provided an email address for hospital registration. An email was resent a month after the initial invitation if a survey was not received by the patient. For all patients, a paper survey with a self-addressed, stamped return envelope was mailed. Patients rated each question on a scale of 1-7, where 1 was "Strongly disagree," 7 was "Strongly agree," and 4 was "Neutral." The responses were averaged and interpreted according to the final score.

Participants were offered the opportunity to submit their email at the end of the study to be entered in a draw to receive a Can $\$ 100$ gift card.

\section{Referring Provider and Potential Consultant Semistructured Interviews}

In the email invitations mentioned above (see Patient Survey section), referring providers were invited to participate in a semistructured interview exploring the perceived impact, current use, and attitudes and opinions toward teledermatology. Similarly, potential consultant dermatologists identified from a convenience sample of dermatologists in academic practice in the same hospital setting, who could potentially participate in a teledermatology service, were recruited via email for the semistructured interviews. Interview guidelines were prepared using the categories of the CHI Benefits Evaluation Framework to complement other data-collection strategies assessing satisfaction, use, educational benefits, and experience and attitudes toward teledermatology.
The primary author conducted interviews over a 3-month period after study initiation, with no other parties present. The interviews were audio-recorded and subsequently transcribed verbatim from the recordings by a professional transcription service.

\section{Data Analysis}

\section{Chart Review}

Demographic and clinical information including complaints and diagnoses was collected. The primary author characterized complaints as "lesion," "rash," or "other," depending on whether the consultation was consistent with multiple or progressive skin findings over a generalized area (rash) or a single, stable skin finding in a localized area (lesion). We recorded the immediate follow-up plan including recommendation for subsequent in-person consultation, optional in-person consultation if the issue was not resolved by the prescribed method, and the proposed timing.

\section{Referring Provider and Patient Surveys}

Results from the Likert scales were collated, and the scores averaged with standard deviation. Free-form text answers were collated and reviewed using word cloud analysis and manual inspection for incorporation of the patterns or pertinent feedback into the final triangulation.

\section{Referring Provider and Potential Consultant Interviews}

For each set of interviews, the primary author and a secondary independent reviewer conducted independent qualitative analyses according to the interpretive description [11]. The transcripts were sequentially reviewed and evaluated with reference to categories from the $\mathrm{CHI}$ Benefits Evaluation Framework. Thematic analysis was used to identify unique emerging concepts potentially beyond the scope of the interview guide. The independent reviewers submitted their qualitative analyses to the primary author for review. Identified themes from both sets of analyses were included in the final mixed-methods analysis. No discordant themes required dispute management by a third party.

\section{Mixed-Methods Concurrent Triangulation}

For the final overarching analysis, we used the CHI Benefits Evaluation Framework to organize a mixed-methods concurrent triangulation strategy that used both qualitative and quantitative assessment methods. We added the evaluative components of potential educational benefits to this strategy. Emergent themes derived from any component were triangulated with other data analyses to support the conclusions.

\section{Results}

\section{Chart Review}

A total of 76 participants used the service between November 2016 and December 2017, including 17 (22\%) pediatric patients, 3 pregnant patients, 28 men $(37 \%)$, and 48 women $(63 \%)$. Consultation data for all patients were subjected to chart review. The average age of patients using the service was 39.3 years, and the average response time was $23.5 \mathrm{~h}$, with a minimum response time of $0.5 \mathrm{~h}$ and a maximum time of $142.6 \mathrm{~h}$ ( 6 days). 
Clinical characteristics were grouped into diagnostic dermatology categories, similar to previous teledermatology evaluations [12], and are presented in Table 2. Each case was broadly categorized into an easily recognizable presenting complaint: a "rash," which presents in multiple areas of the skin with the same general appearance, most typically represented by eczematous dermatoses, infections, or reactive skin conditions; a "lesion," which is a focal, persistent eruption on the skin, typified by benign and malignant growths; or a "question" about a treatment (Table 3). Of all cases, 12 (16\%) required a subsequent in-person visit.

We assumed that clinicians would use photographs from a patient visit to their office; however, in $14 \%$ of all consultations, parent- or patient-initiated photographs were used. In 6 (35\%) of the pediatric cases, photographs for analysis were provided by the parents, and 5 adult patients provided their own photographs to the clinician. None of these patients required additional photographs or in-person follow-up, and cases wherein the data were available, the conditions were appropriately resolved. In one case, the parent-initiated photograph showed evidence of a rare condition that occurs only under specific conditions.

Our results showed that it was possible to manage $94 \%$ of "rashes" by teledermatology alone, but only 59\% of "lesions" could be managed by this method. Additionally, in 21 cases (27\%), the primary management aimed to increase the prescribed potency of or choose a more-effective vehicle for the topical steroid used. Finally, in at least one case, a response time of 24 $h$ permitted initiation of therapy to prevent postherpetic neuralgia complications of herpes zoster; however, the recommended 72-h time window for treatment [13] would have been exceeded if the maximum response time of the service (1 week) was applied in this case.

\section{Referring Provider Survey}

Of the 14 invitations sent, we received 11 responses for the online survey ( $79 \%$ response rate). Responses were averaged and interpreted according to the final score. The results of the survey and the Likert interpretation of the average score are presented in Table 4. Feedback was generally very positive for satisfaction and educational value. The clinicians reported that the service did not save any time, but increased the administrative time. However, they indicated that the benefits of the service outweighed the lost time and the service had educational value. No adverse events were reported.

\section{Patient Survey}

A total of 76 patients were sent paper surveys and 26 patients, who had provided an email address for provider registration at the institution, were sent a duplicate email invitation.

We received 22 responses (29\%). Patients were generally satisfied with the service and reported that it saved time and money and prevented them from missing work. However, their views were divided when they were asked if they "prefer to use this system instead of going to see a specialist in-person." Their responses were instructive: Some patients indicated that they generally prefer in-person consultations, as they provide a greater opportunity to ask questions and clarify the rationale for therapeutic choices. These results are summarized in Table 5.

Table 2. Clinical characteristics of the consultations grouped by diagnostic categories in dermatology.

\begin{tabular}{lll}
\hline Diagnosis & Cases $(\mathrm{N}=76), \mathrm{n}(\%)^{\mathrm{a}}$ & $\begin{array}{l}\text { Patients transitioned to in-person } \\
\text { consultation }(\mathrm{N}=76), \mathrm{n}(\%)^{\mathrm{b}}\end{array}$ \\
\hline Eczematous or inflammatory (eczema or contact dermatitis) & $30(39)$ & $1(1)$ \\
Infection requiring Intervention (fungal, viral, or bacterial) & $10(13)$ & $0(0)$ \\
Urticarial or self-limited (morbilliform eruptions or pediatric urticaria) & $7(9)$ & $1(1)$ \\
Lesion (malignant, premalignant, indeterminate, or benign) & $21(28)$ & $9(43)$ \\
Other (genetic, acneiform, etc) & $8(11)$ & $1(1)$ \\
Total & $76(100)$ & $12(16)$ \\
\hline
\end{tabular}

${ }^{\text {a }}$ Total number of cases seen within the category.

${ }^{\mathrm{b}}$ Cases where the primary and only recommendation was that the patient visit a dermatologist in-person.

Table 3. Clinical characteristics of the consultations grouped by the presenting complaint.

\begin{tabular}{lll}
\hline Presenting complaint & Cases (N=76), $\mathrm{n}(\%)$ & $\begin{array}{l}\text { Patients transitioned to in-person } \\
\text { consultation }(\mathrm{N}=76), \mathrm{n}(\%)\end{array}$ \\
\hline Rash & $53(70)$ & $3(6)$ \\
Lesion & $22(29)$ & $9(41)$ \\
Question & $1(1)$ & $0(0)$ \\
Total & $76(100)$ & $12(16)$ \\
\hline
\end{tabular}


Table 4. Health care providers' responses to the survey ( $\mathrm{N}=11)$.

\begin{tabular}{lll}
\hline Question & Mean (SD) & Interpretation \\
\hline The responses from the dermatologist were complete. & $6.6(0.6)$ & Strongly agree \\
The responses from the dermatologist were timely. & $6.8(0.4)$ & Strongly agree \\
The service was reliable. & $6.5(0.8)$ & Strongly agree \\
I was satisfied with the answers to the clinical questions. & $6.5(0.7)$ & Strongly agree \\
I was satisfied with the educational value of the system. & $6.4(0.9)$ & Strongly agree \\
The service was easy to use. & $6.6(0.5)$ & Strongly agree \\
The educational value of the e-consults was generally superior to that of in-person consult letters. & $5.5(1.2)$ & Agree \\
This service saves me time. & $4.9(1.2)$ & Neither \\
This service provides advantages to me that outweigh any lost time. & $5.8(1.0)$ & Agree \\
This service saves patients time. & $6.8(0.4)$ & Strongly agree \\
This service saves the health care system resources. ${ }^{\text {a }}$ & $6.5(0.7)$ & Strongly agree \\
\hline
\end{tabular}

${ }^{a}=10$.

Table 5. Patients' responses to the surveys.

\begin{tabular}{llll}
\hline Question & $\mathrm{n}(\%)$ & Mean (SD) & Interpretation \\
\hline I would want to use this service again. & $22(100)$ & $6.7(0.6)$ & Strongly agree \\
I would recommend this service to a friend or family member. & $21(95)$ & $6.6(0.7)$ & Strongly agree \\
I was satisfied with how my skin issue was managed. & $21(95)$ & $6.4(1.0)$ & Strongly agree \\
I am comfortable with the idea of a physician I have never met evaluating my skin condition \\
based on pictures. & $22(100)$ & $6.2(0.7)$ & Strongly agree \\
I would prefer to use this system instead of going to see a specialist in-person. & $20(91)$ & $4.9(1.8)$ & Neutral \\
I would recommend this type of medical care to a friend or family member. & $22(100)$ & $5.8(1.1)$ & Agree \\
I think that the government should pay for me to talk to the dermatologist online directly. & $21(95)$ & $5.4(1.8)$ & Agree \\
$\begin{array}{l}\text { I would personally pay to talk to the dermatologist online directly if it was not paid for by the } \\
\text { government. }\end{array}$ & $20(91)$ & $3.7(2.0)$ & Disagree \\
$\begin{array}{l}\text { I would have liked to see what was said between my family doctor and the dermatologist. } \\
\text { Overall, this service saved me time. }\end{array}$ & $22(100)$ & $5.2(1.8)$ & Agree \\
Overall, this service saved me money. & $22(100)$ & $6.6(0.6)$ & Strongly agree \\
Because of this service, I missed less work for my health appointments. & $15(68)$ & $5.7(1.8)$ & Agree
\end{tabular}

\section{Referring Provider and Potential Consultant Interviews}

A total of 8 interviews of 4 referring providers who had experience with the system and 4 consultant dermatologists who had experience with other implementations of teledermatology or were open to participating in the service were analyzed.

Efficiency of care emerged as a theme. For referring providers...

...the option to send a photo with a quick email and get a response really quickly is actually a huge asset... [The patients are] really happy not to go and see another physician for the same matter because some things are easily treatable or diagnosed through that service. [Interview F2]
Although dermatologists were open to email communication, they expressed concern that additional administrative overhead may prevent uptake; for example, one dermatologist felt that,

[In some systems,] the platform is not efficient, it doesn't keep track of cases seen, billing codes, billing numbers, the kind of information that we need in the logistics of how we provide care... a proper kind of charting system or billing system. [Interview D3]

Interviews supported the data from patient surveys that both providers and patients were satisfied with the service. One provider stated,

The patients are absolutely thrilled because...You can get back to them so quickly with such an informed opinion. [Interview F4] 
Table 6. Summary and interpretation of the unified mixed-methods evaluation using the Canada Health Infoway Benefits Evaluation Framework [9].

\begin{tabular}{|c|c|c|c|c|}
\hline Component & Chart review & Quantitative (surveys) & Qualitative (interviews) & Interpretation \\
\hline $\begin{array}{l}\text { System quality: func- } \\
\text { tionality, performance, } \\
\text { and security }\end{array}$ & $\begin{array}{l}\text { The technology demon- } \\
\text { strated robustness with } \\
\text { no lost messages }\end{array}$ & $\begin{array}{l}\text { Providers "strongly agreed" that } \\
\text { the service was reliable and easy } \\
\text { to use }\end{array}$ & $\begin{array}{l}\text { Referring providers and der- } \\
\text { matologists found the institu- } \\
\text { tional email to be an appropri- } \\
\text { ate medium, despite the in- } \\
\text { creased administrative burden }\end{array}$ & $\begin{array}{l}\text { Institutional email facilitated } \\
\text { a functional service with ade- } \\
\text { quate performance and securi- } \\
\text { ty }\end{array}$ \\
\hline
\end{tabular}

Information quality: All consultations were content and availability generally completed with one question and one response siveness

Use: behavior, self-reported use, and intention to use

User satisfaction: competency, satisfaction, and ease of use

Quality: safety and out- In cases of independent comes

Access: ability to access services, and patient and caregiver participation
The average response time was consistent with that of other systems in the literature [14], and in at least one case, potentially prevented morbidity

Unexpectedly, parentand patient-initiated photos were used. Recent research suggests they can be used accurately for diagnosis while saving additional visits [15]

A total of $92.8 \%$ (13 of 14) providers used the service more than once follow-up, the results supported the diagnosis and management plan of the teledermatology consultant

The service was used for a broad demographic of patients and complaints, suggesting no barriers to
Service quality: respon-

Providers "strongly agreed" that the responses were complete, provided satisfactory answers to the clinical questions, and had educational value

Providers "strongly agreed" that the responses were timely. Patients also commented positively on the rapid response access

Productivity: efficiency, For the Ontario billing care coordination, and net cost codes, managing $84 \%$ of the consultations by teledermatology results in $30 \%$ savings overall for visits to consultant dermatologists $^{\mathrm{a}}$
Interviewees spoke positively about the structure of the consultations; one interviewee commented, "What I like to have the best is a plan that has multiple steps if the first doesn't work" (Interview F1)

"It works because your notes are good and your turnaround time is fast" (Interview F5)

A consultation format that incorporates morphology, diagnosis, reasoning used, and a treatment ladder was satisfactory and educational to providers

A 24-h average response rate was appropriate for most outpatient clinical situations
Although the service did not generally save providers time, they "agreed" that the benefits outweighed the increased administrative burden

Providers and patients "strongly agreed" that they were satisfied with the outcomes of the system

In interviews, dermatologists expressed that they would be more likely to offer the service if it represented an integrated workflow with medical records and billing

"Most patients that I follow up with afterwards are really happy that they didn't have to go to any more measures (to be treated)" (Interview F2)

No adverse events were reported in the survey. Patients "strongly agreed" that they would use this service again or recommend its use. Patient comments supported the idea that the correct management plan was identified

Patients "strongly agreed" that they were comfortable if a physician they had never met evaluated their skin. However, they also "agreed" they would like to know what was communicated between the consultant and referring physician; this idea was supported by patient comments

Providers "strongly agreed" that the service saved health care system resources. Patients "agreed" that the service saved them time and money and resulted in less work missed

No adverse events or areas for improvement were reported in interviews

Interviewees cited several patient factors (anxiety, sensitive locations, etc) that could theoretically prevent use, but no barriers noted in interviews actually prevented use

Both potential dermatologists and referring providers characterized institutional email as an efficient tool for consultations. This efficiency increased when email communication was used between the provider and the patients
Although the evident benefits to patients and the educational value ameliorates the burden to providers, a more integrated workflow may have increased utilization by referees and potential consultants

The service demonstrated satisfaction for providers and patients

Intrainstitutional teledermatology (concordant with existing literature) was safe and effective

Although easy to access, further integration of the patien into the physician-physician communication channel may have been beneficial

Intrainstitutional teledermatology increased productivity and efficiency even when geography was not a barrier to care

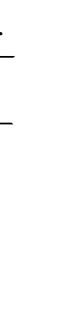


real time or very promptly, it's a better learning experience for me and I can do a better job. [Interview F4]

Finally, referring providers noted that the service was very useful in situations when they identified the diagnosis but wanted to be up to date on management. One provider stated,

\section{Next time that I see a similar presentation I know how to treat it and then if it doesn't work then I know where I should go. [Interview F2]}

Dermatologists agreed that they were more comfortable answering management questions than diagnostic questions in telemedicine or remote situations; one dermatologist said,

I like questions about disease entities and management, as long as the diagnosis has already been established. [Interview D4]

\section{Mixed-Methods Analysis}

\section{Triangulation Using the CHI Benefits Evaluation Framework}

In the concurrent triangulation evaluation, we correlated the categories of the CHI Benefits Evaluation Framework with our multiple lines of inquiry (Table 6). The hypothesis of net benefit was supported by both qualitative and quantitative evidence.

\section{Discussion}

\section{Principal Findings}

The concurrent triangulation analysis was consistent with our hypothesis: The intrainstitutional teledermatology service was effective and satisfying to providers and patients even when geographic access was not a barrier. Store-and-forward teledermatology demonstrated diagnostic concordance [17]. In addition, a previous systematic review supported the idea that teledermatology is associated with high satisfaction [18]. Prior work has suggested that cost-effectiveness is not a universal feature of teledermatology [19] and would be highly dependent on regional factors. In our study, the service demonstrated $30 \%$ savings in visitation fees [16], and according to the patients, the service saved time and money and prevented them from missing work, which are important components of social cost.

To our knowledge, this is one of the first few studies to investigate the educational potential of teledermatology for referring providers embedded in a consultation service. Other studies have reported the value of incorporating trainees into the teleconsultation process [20] or initiatives such as project ECHO [21] that explore virtual education separate from the service. In our initiative, we found that an appropriately structured consultation note that explains clinical reasoning and offers a treatment ladder was educational and helpful to the referring provider. Furthermore, both dermatologists and referring providers suggested that the greatest educational value of this service was management, not diagnosis. This is supported by the chart review, which showed that $27 \%$ of all recommendations involved only alteration of the existing topical treatment. A dermatologist noted, "We all know that the challenge with skin diseases; people don't think about it from a morphology point of view. They think about it as; that person I saw with psoriasis three years ago, this looks like that, right? And so that educated piece, in terms of diagnostics, I think would be lost." (Interview D4). Incorporating formal management and educational initiatives into teleconsultation is an area of potential expansion and study in the future.

In our chart review, $41 \%$ of lesions required a subsequent in-person visit compared to only $6 \%$ of rashes. Therefore, in the future, such a service would be most productive and efficient if it targeted the management of "rashes" alone. This finding is in line with the view of dermatologists who expressed concern about their comfort with regard to managing lesions by traditional teledermatology and the abovementioned educational findings: There are fewer management options for lesions and therefore potentially less educational value in the discussion of those consultations.

Future services should consider a 24-h consultation response time to manage the most-serious outpatient clinical scenarios. Other pilot services in the literature meet or surpass this response time [22,23]. Important clinical conditions that are time sensitive, meaning that they need $\leq 24 \mathrm{~h}$ for diagnosis and rapid management in dermatology, are infections requiring intervention and serious drug rashes [24] because of the risk of significant morbidity and mortality. In our study, there was only one case of a treatable infection where identification within the period prevented morbidity; however, this may be because referring providers would less likely consider using teledermatology for high-acuity dermatoses if the "maximum" response time allotted was 1 week. However, setting the response time too low may decrease the number of potential dermatologists willing to participate in the service, unless adequately remunerated or alternatively structured (eg, shared "on-call" responsibilities or triage responsibilities delegated to trainees or other health care professionals).

\section{Limitations}

One limitation of this study is that this was a small case study at a single institution in a region that is supportive of virtual care. Therefore, the results may not be generalizable. As the primary author is currently the only consulting teledermatologist in our institution, there may be a better way to provide improved care and faster response times than a "usual case" scenario, which could lead to potential bias towards positivity. In addition, follow-ups or "second opinion" consultations may not have been accounted for if they were referred to other care clinics in the city outside the circle of care of the institution.

\section{Conclusion}

This is the first reported study on intrainstitutional teledermatology using a mixed-methods approach to explore the benefits of teledermatology, namely, rapid access, high satisfaction, safe and effective clinical outcomes, and increased efficiency and productivity in the health care system. The integration of teledermatology into a routine clinical workflow has remarkable potential value, irrespective of existing access to consultative dermatology. Specifically, by reducing healthcare visits, patients can save time and money and avoid missing work. Additionally, this study provides evidence that 
management of rashes is ideal via teledermatology, which may lead to better outcomes because of the rapid response and high proportion of cases that can be managed through teledermatology alone. This finding is concordant with the expressed opinions of dermatologists in our study who did not want to assess lesions with traditional teledermatology. The impact and satisfaction of an intrainstitutional teledermatology service that primarily targets rashes and, according to our study, ideally provides responses within $24 \mathrm{~h}$ to maximize safety, is worth evaluating in future studies. Further research is necessary to elucidate the educational value of intrainstitutional teledermatology for referring providers and its potential for saving costs.

\section{Conflicts of Interest}

None declared.

\section{References}

1. Russo L, Campagna I, Ferretti B, Agricola E, Pandolfi E, Carloni E, et al. What drives attitude towards telemedicine among families of pediatric patients? A survey. BMC Pediatr 2017 Dec 17;17(1):21 [FREE Full text] [doi:

10.1186/s12887-016-0756-x] [Medline: 28095894]

2. Yoo J, Rigel DS. Trends in dermatology: geographic density of US dermatologists. Arch Dermatol 2010 Jul;146(7):779. [doi: 10.1001/archdermatol.2010.127] [Medline: 20644040]

3. Canadian Dermatology Association. 2018. Find a dermatologist URL: https://dermatology.ca/public-patients/ about-dermatology/find-a-dermatologist/ [accessed 2018-09-01] [WebCite Cache ID 71a6rtiq7]

4. Feng H, Berk-Krauss J, Feng PW, Stein JA. Comparison of Dermatologist Density Between Urban and Rural Counties in the United States. JAMA Dermatology 2018 Nov 01;154(11):1265-1271. [doi: 10.1001/jamadermatol.2018.3022] [Medline: 30193349]

5. Carter Z, Goldman S, Anderson K, Li X, Hynan LS, Chong BF, et al. Creation of an Internal Teledermatology Store-and-Forward System in an Existing Electronic Health Record: A Pilot Study in a Safety-Net Public Health and Hospital System. JAMA Dermatol 2017 Jul 01;153(7):644-650 [FREE Full text] [doi: 10.1001/jamadermatol.2017.0204] [Medline: 28423156]

6. Fabbrocini G, De Vita V, Pastore F, D'Arco V, Mazzella C, Annunziata MC, et al. Teledermatology: from prevention to diagnosis of nonmelanoma and melanoma skin cancer. Int J Telemed Appl 2011;2011:125762 [FREE Full text] [doi: 10.1155/2011/125762] [Medline: 21776252]

7. Naka F, Lu J, Porto A, Villagra J, Wu ZH, Anderson D. Impact of dermatology eConsults on access to care and skin cancer screening in underserved populations: A model for teledermatology services in community health centers. J Am Acad Dermatol 2018 Dec;78(2):293-302. [doi: 10.1016/j.jaad.2017.09.017] [Medline: 29061478]

8. Krupinski E, Burdick A, Pak H, Bocachica J, Earles L, Edison K, et al. American Telemedicine Association's Practice Guidelines for Teledermatology. Telemed J E Health 2008 Apr;14(3):289-302. [doi: 10.1089/tmj.2007.0129] [Medline: 18570555]

9. Canada Health Infoway. 2018. Benefits Evaluation Framework URL: https://www.infoway-inforoute.ca/en/what-we-do/ research-and-insights/benefits-evaluation/benefits-evaluation-framework [accessed 2018-09-01] [WebCite Cache ID 71a7q6GWZ]

10. Survey Monkey. URL: https://www.surveymonkey.com/ [accessed 2018-11-02]

11. Thorne S. Interpretive Description: Qualitative Research for Applied Practice. New York, NY: Routledge; Mar 21, 2016.

12. Nelson C, Takeshita J, Wanat KA, Bream KDW, Holmes JH, Koenig HC, et al. Impact of store-and-forward (SAF) teledermatology on outpatient dermatologic care: A prospective study in an underserved urban primary care setting. $\mathrm{J}$ Am Acad Dermatol 2016 Mar;74(3):484-90.e1. [doi: 10.1016/j.jaad.2015.09.058] [Medline: 26679528]

13. Whitley R, Volpi A, McKendrick M, Wijck A, Oaklander A. Management of herpes zoster and post-herpetic neuralgia now and in the future. Journal of Clinical Virology 2010 May;48:S20-S28. [doi: 10.1016/S1386-6532(10)70005-6]

14. Callahan CW, Malone F, Estroff D, Person DA. Effectiveness of an Internet-based store-and-forward telemedicine system for pediatric subspecialty consultation. Arch Pediatr Adolesc Med 2005 Apr;159(4):389-393. [doi:

10.1001/archpedi.159.4.389] [Medline: 15809396]

15. O'Connor DM, Jew OS, Perman MJ, Castelo-Soccio LA, Winston FK, McMahon PJ. Diagnostic Accuracy of Pediatric Teledermatology Using Parent-Submitted Photographs: A Randomized Clinical Trial. JAMA Dermatol 2017 Dec 01;153(12):1243-1248. [doi: 10.1001/jamadermatol.2017.4280] [Medline: 29141082]

16. Ministry of Health and Long Term Care. Ontario Schedule of Benefits: Physician Services Under the Health Insurance Act URL: http://www.health.gov.on.ca/en/pro/programs/ohip/sob/physserv/sob master11062015.pdf [accessed 2018-09-01] [WebCite Cache ID 72BL7Jgxc]

17. Du Moulin MF, Bullens-Goessens YI, Henquet CJ, Brunenberg DE, de Bruyn-Geraerds DP, Winkens RA, et al. The reliability of diagnosis using store-and-forward teledermatology. J Telemed Telecare 2003 Jun;9(5):249-252. [doi: 10.1258/135763303769211247] [Medline: 14599326] 
18. Mounessa JS, Chapman S, Braunberger T, Qin R, Lipoff JB, Dellavalle RP, et al. A systematic review of satisfaction with teledermatology. J Telemed Telecare 2018 May;24(4):263-270. [doi: 10.1177/1357633X17696587] [Medline: 28350281]

19. Snoswell C, Finnane A, Janda M, Soyer HP, Whitty JA. Cost-effectiveness of Store-and-Forward Teledermatology: A Systematic Review. JAMA Dermatol 2016 Jun 01;152(6):702-708. [doi: 10.1001/jamadermatol.2016.0525] [Medline: 27074289]

20. Patel J, Parr K, Buehler-Bota T, Hood AF. Integrating Outpatient Teledermatology Education Into the Dermatology Resident Curriculum. J Grad Med Educ 2016 Jul;8(3):468-469 [FREE Full text] [doi: 10.4300/JGME-D-15-00792.1] [Medline: 27413472]

21. Katzman J, Comerci G, Boyle JF, Duhigg D, Shelley B, Olivas C, et al. Innovative telementoring for pain management: project ECHO pain. J Contin Educ Health Prof 2014;34(1):68-75. [doi: 10.1002/chp.21210] [Medline: 24648365]

22. McGoey S, Oakley A, Rademaker M. Waikato Teledermatology: a pilot project for improving access in New Zealand. J Telemed Telecare 2015 Oct;21(7):414-419. [doi: 10.1177/1357633X15583216] [Medline: 26033844]

23. Nami N, Massone C, Rubegni P, Cevenini G, Fimiani M, Hofmann-Wellenhof R. Concordance and time estimation of store-and-forward mobile teledermatology compared to classical face-to-face consultation. Acta Derm Venereol 2015 Jan;95(1):35-39 [FREE Full text] [doi: 10.2340/00015555-1876] [Medline: 24889827]

24. Usatine RP, Sandy N. Dermatologic emergencies. Am Fam Physician 2010 Oct 01;82(7):773-780 [FREE Full text] [Medline: $\underline{20879700]}$

\section{Abbreviations \\ CHI: Canada Health Infoway}

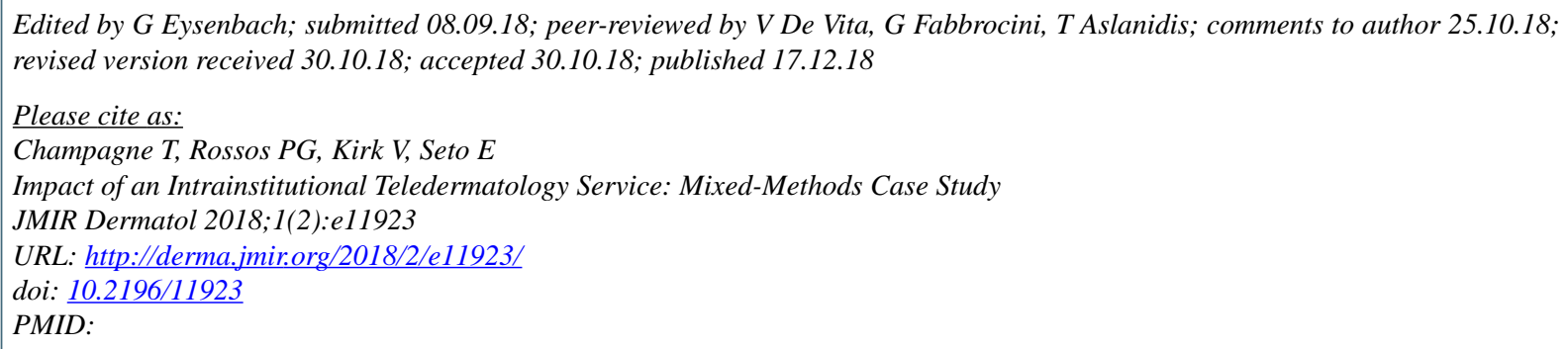

(CTrevor Champagne, Peter G Rossos, Veronica Kirk, Emily Seto. Originally published in JMIR Dermatology (http://derma.jmir.org), 17.12.2018. This is an open-access article distributed under the terms of the Creative Commons Attribution License (https://creativecommons.org/licenses/by/4.0/), which permits unrestricted use, distribution, and reproduction in any medium, provided the original work, first published in JMIR Dermatology Research, is properly cited. The complete bibliographic information, a link to the original publication on http://derma.jmir.org, as well as this copyright and license information must be included. 